ORIGINAL ARTICLE

\title{
Thinking beyond organism energy use: a trait-based bioenergetic mechanistic approach for predictions of life history traits in marine organisms
}

\author{
Gianluca Sarà ${ }^{1}$, Alessandro Rinaldi ${ }^{1,2}$ \& Valeria Montalto ${ }^{1}$ \\ 1 Dipartimento di Scienze della Terra e del Mare, Università di Palermo, Palermo, Italy \\ 2 Dipartimento di Scienze Biologiche ed Ambientali, Università di Messina, Messina, Italy
}

Keywords

Dynamic energy budget model; functional trait-based bioenergetic approach; life history traits; marine ectotherms.

\section{Correspondence}

G. Sarà, Dipartimento di Scienze della Terra e del Mare, Università di Palermo, Viale delle Scienze, Ed. 16, 90128 Palermo, Italy.

E-mail: gianluca.sara@unipa.it

Accepted: 11 August 2013

doi: 10.1111/maec.12106

\begin{abstract}
The functional trait-based bioenergetic approach is emergent in many ecological spectra, from the conservation of natural resources to mitigation and adaptation strategies in a global climate change context. Such an approach relies on being able to exploit mechanistic rules to connect environmental humaninduced variability to functional traits (i.e. all those specific traits defining species in terms of their ecological roles) and use these to provide estimates of species life history traits (LH; e.g. body size, fecundity per life span, number of reproductive events). LHs are species-specific and proximate determinants of population characteristics in a certain habitat. They represent the most valuable quantitative information to investigate how broad potential distributional boundaries of a species are, and to feed predictive population models. There is much to be found in the current literature that describes mechanistic functional trait-based bioenergetics models, using them to test ecological hypotheses, but a mathematical framework often renders interpretation and use complicated. Here, we wanted to present a simpler interpretation and description of one of the most important recent mechanistic bioenergetic theories: the dynamic energy budget theory by Kooijman (Dynamic Energy Budget Theory for Metabolic Organisation, 2010, Cambridge University Press, Cambridge). Our main aim was to disentangle those aspects that at first reading may seem too mathematically challenging to many marine biologists, ecologists and environmental scientists, and present them for use in mechanistic applications.
\end{abstract}

\section{Introduction}

Most recent reviews and papers lament the substantial lack of an interpretational perspective of how anthropogenic disturbance affects natural systems and stress the need for reliable, predictive models to interpret the future' in a 'disturbed world' (Loreau 2010; Denny \& Benedetti-Cecchi 2012). The functional trait-based bioenergetic approach seems to be a practical solution to providing quantitatively accurate predictions of species abundance in a rapidly changing world (Araujo \& Rahbek
2006). Moreover, it can be used to investigate the link between ecological responses and human disturbance, and to study the possible implications that this link has on biodiversity and ecosystem functioning. The approach is now emergent in many ecological spectra, from the conservation of natural resources to mitigation and adaptation strategies to be adopted in a global climate change context (Webb et al. 2010).

The most reliable and accepted approach is based on the dynamic energy budget theory (DEB; Kooijman 2010), which mechanistically depicts temperature-dependent 
metabolic processes with precision and enables us to make more accurate predictions of organisms' growth performance. This has been successfully demonstrated on land with lizards (Kearney 2012; Kearney et al. 2012) and in marine habitats with bivalves (Pouvreau et al. 2006; Kearney et al. 2010; Sarà et al. 2011, 2012, 2013; Saraiva et al. 2012), crustaceans and fish (e.g. Jusup et al. 2011; Pecquerie et al. 2011). DEB even seems a good candidate to predict distributions of invasive organisms (Sarà et al. in press-a) or threatened species (sensu Kearney 2012), as well as a simple tool which, starting from organismal functional traits and a few mechanistic rules (Kooijman 2010), is able to provide basal information (viz. based on species identity) about the suitability of areas potentially devoted to aquaculture (Rinaldi et al., submitted), the sustainability of aquaculture practices (integrated multitrophic aquaculture; Sarà et al. 2012) and fishery (Einarsson et al. 2011). Thus, we need to increase our understanding of potential fields of ecological applications, as well as possible shortcomings of that approach.

Such an approach relies on being able to exploit mechanistic rules to connect environmental human-induced variability to functional traits (Schoener 1986; Diaz \& Cabido 2001) and in turn functional traits to species life history (LH; Stearns 1992) traits starting from a wholeorganismal level, and to population dynamics (Cheung et al. 2011) and community structures (Laughlin et al. 2012).

By functional, we mean all those specific traits defining species in terms of their ecological roles (Diaz \& Cabido 2001), thereby the species' identity. Most marine organisms are ectotherms such as algae, seagrasses, molluscs, crustaceans, polychaetes and fish. In these, the traits usually include tolerance and sensitivity to environmental conditions, e.g. physiological thermal tolerance limits (Kearney \& Porter 2009) or mechanisms involved in the reaction to hypoxia (Pörtner 2010) and hypercapnia (Hendriks et al. 2010). Tolerance limits include the ability of each species to maintain metabolic machinery and biological performances throughout space and time (Sokolova et al. 2012). The ability to obtain energy from food is also a functional trait, and follows the so-called functional response (Holling 1959; Denny \& Benedetti-Cecchi 2012) or all those traits, both behavioural (e.g. swimming behaviour, habitat use, mating system) and morphological (e.g. shape: the mega-parameters of Schoener 1986), concurring with the optimisation of energetic income (Krebs \& Davies 1992) and the magnitude of LH traits. Functional traits are therefore directly involved in the magnitude of $\mathrm{LH}$ traits and the fitness magnitude of every species (Roff 1992; Stearns 1992; Charnov 1993), for example body size and the number of reproductive events per life span.
These species-specific LH traits are the most important proximate determinants of population characteristics (e.g. density and structure) in a certain habitat, and of how large the potential distributional area of the species is (Cheung et al. 2011). All possible aspects of that complex ecological mosaic involving habitat characteristics, single species performance boundaries, population dynamics, community and ecosystem tiles deserve equally close attention. Wider reflection is required to correctly trace a road map for the future of ecological studies, with the aim of investigating the reasons for the current ecological equilibriums. Once that understanding has been increased, our ability to predict future consequences for biodiversity under the expected growing human pressure on ecosystems will be enhanced (Hoegh-Guldberg \& Bruno 2010).

The mechanistic view and models are at the core of the mosaic. Models like these are often based on a complex mathematical framework. Therefore, we herein provide a simpler interpretation of one of the most important contemporary mechanistic bioenergetic theories, which has spawned several dozens of studies in the last few years: the DEB theory by Kooijman (2010). At first reading, some aspects of this theory may appear too mathematically complex for many ecologists and environmental scientists. Our main aim is to extract the most salient aspects of mechanistic applications, present them in a simple way and also discuss the ways in which the approach can be applied. Possible shortcomings will also be taken into account.

\section{The DEB Model}

Dynamic energy budget comprises a complete theoretical asset, at the whole organismal level, to link habitat, functional traits and life history of any living organism. It is the core of the 'functional trait-based approach' (Kearney \& Porter 2009) and it represents the 'quantitative from scratch framework' providing first principles (Aristotle ad sensum) to investigate mechanistically:

1 How every species manages the available energy from the habitat, and

2 How the utilisation of this energy is prioritised, i.e. the important choices that one organism has to activate unconsciously to optimise fitness along the life span (sensu Charnov \& Krebs 1974; Loreau 2010).

These two aspects are not based on the 'feeling' of an organism, as common anthropocentric views might suppose; they are based on strict physical, chemical and thermodynamic laws (the so-called first principles) governing the functioning of the world (Denny \& Benedetti-Cecchi 2012). Thus, the entirety of first principle's power can be exploited to provide predictive scenarios of organismal 
functioning. They provide a fundamental explanation of, for example, how, why and where organisms are present (or absent) throughout their distributional ranges (at the net of biotic interactions), how one organism is able to respond to environmental variability and multiple anthropogenic stressors (Sokolova et al. 2012), and the magnitude and spatio-temporal scale of ecological response. All of this is basal information that defines the role of one species in a community (Webb et al. 2010; Laughlin et al. 2012).

The mechanistic properties of this approach rely on energy and matter flows from habitat through organisms. But flows of energy and matter (and time) through habitats and organisms are subjected to conservation laws (Kooijman 2010) and, consequently, they are traceable (and budgetable) processes. We can use these principles to mechanistically predict the functioning of each species and thereby the magnitude and variability of $\mathrm{LH}$ traits (Kearney et al. 2010, 2012; Sarà et al. in press-a).

\section{Before we start: the simple metaphor of the 'washbasin'}

The simplicity of organismal functioning rules from an energetic viewpoint can be equated well to that of the washbasin (M. Kearney, unpublished observations). Energy flowing from the habitat (here, the large water container at the back of the washbasin) is modulated by numerous functional traits (the tap; e.g. the Holling functional response accounting for mutually exclusive functions like searching, management, ingestion of the food available and assimilation; Koen-Alonso 2007). It reaches the washbasin and accumulates into reserves (the water present in the washbasin; i.e. stored as metabolites such as proteins, lipids, carbohydrates). Two drain pipes of different diameter leave the washbasin and allow the water (energy reserve) to reach two main (virtually separate) containers: the first is that of structures (i.e. the body structures) accounting for the most of the flow rate (the so-called kappa); the second pipe is narrower than the first and supplies energy to the reproduction container (i.e. 1-kappa). These two flows are connected by a tradeoff (the Kooijman kappa rule; Kooijman 2010) and they are directly linked to the amount of reserves, which depends on the available energy manageable by the organisms, which, in turn, depends on the ability of organisms to manage the amount of energy available in the habitat. If for some reason the washbasin empties, there is no more energy to refill the two containers, and structure and reproduction both reduce. This situation will have important repercussions on organismal ability to cope with environmental variability (e.g. obtaining food from the habitat, interacting with other organisms, sustaining an immune-defence system, and producing gametes).

\section{Description of the standard DEB model}

While not every organism possesses vascular supply networks, all organisms mobilise internal energy and store material before metabolites are transported to fuel metabolism. The standard DEB model (Kooijman 2010; Fig. 1) incorporates whole-organism bioenergetics, connecting individual behaviours to population growth via the description of how energy and mass are managed by an organism to maximise ultimate fitness (i.e. Darwinian fitness; Bozinovic et al. 2011) and how metabolic trade-offs are involved in response to different environmental conditions. The manner and the efficiency with which energy flows through an organism varies according to its metabolism; thus it is greatly affected by body size. In the DEB theory, the structural volume $V$ (i.e. the cube of volumetric length) is the key feature that allows body size to be included in the complete budget of the organism. The conversion between physical length $\mathrm{L}$ and $\mathrm{V}$ is performed by including shape coefficient $\left(\delta_{M}\right)$, a dimensionless quantity that, according to the rules of isomorphism, remains unchanged throughout the life cycle of the organism such as $\mathrm{V}^{1 / 3}=\mathrm{L} \times \delta_{\mathrm{M}}$. To transform the measurement of length to structural volume, the following formula is applied: $\mathrm{V}=\left(\delta_{\mathrm{M}} \times \mathrm{L}\right)^{3}$. As shape depends on the type of length measurements, a simple way to obtain an estimation is to exploit the relation between length and wet weight of target species (Sarà et al. 2013) according to the following formula: $\delta_{\mathrm{M}}=\left(\frac{\mathrm{W}_{\mathrm{W}}}{\mathrm{d}_{\mathrm{V}_{\mathrm{w}}}}\right)^{1 / 3} \times \mathrm{L}^{-1}$, where $\mathrm{W}_{\mathrm{W}}$ is the wet weight of flesh tissue, $\mathrm{d}_{\mathrm{V}_{\mathrm{w}}}$ is the specific density for structure, which in most benthic invertebrates is assumed to be equal to $1 \mathrm{~g} \cdot \mathrm{cm}^{-3}$ and $\mathrm{L}$ is the total length $(\mathrm{cm})$. Thus, while $\mathrm{V}$ is an estimate of every single individual (see above), ideally the shape coefficient should be estimated from all individuals belonging to the whole population. In a DEB context, volume and surface area quantities play crucial roles in energetic exchanges and fluxes. For instance, acquisition rates are considered proportional to surface area (and are usually displayed in curly brackets), whereas maintenance rates requiring energetic costs are usually related to volume of biomass (and displayed in square brackets).

The standard DEB model can be roughly considered to be partitioned into two separate large compartments: one (upper compartment in Fig. 1) dealing with a feeding process that describes how energy coming from food is stored as metabolites (e.g. stored proteins, lipids, carbohydrates) and another (lower compartment in Fig. 1) in which the energy is allocated to maintenance and transformed into structures (i.e. growth) and offspring (i.e. reproduction).

The link between the two parts is represented by the reserves, in which all the energy coming from the upper 
Fig. 1. Schematic representation of the standard Dynamic Energy Budget model (Kooijman 2010) and the flux of energy through an organism coming from the environment; numbers close to symbol of energy fluxes follows those reported in

Table 1. *Apart from food, another important constraint in the metabolic process is individual body temperature. In ectotherms, body temperature can be approximated as that in the environment (Lima et al. 2011). We decided to describe the dynamic energy budget (DEB) with suspension feeder bivalves as model.

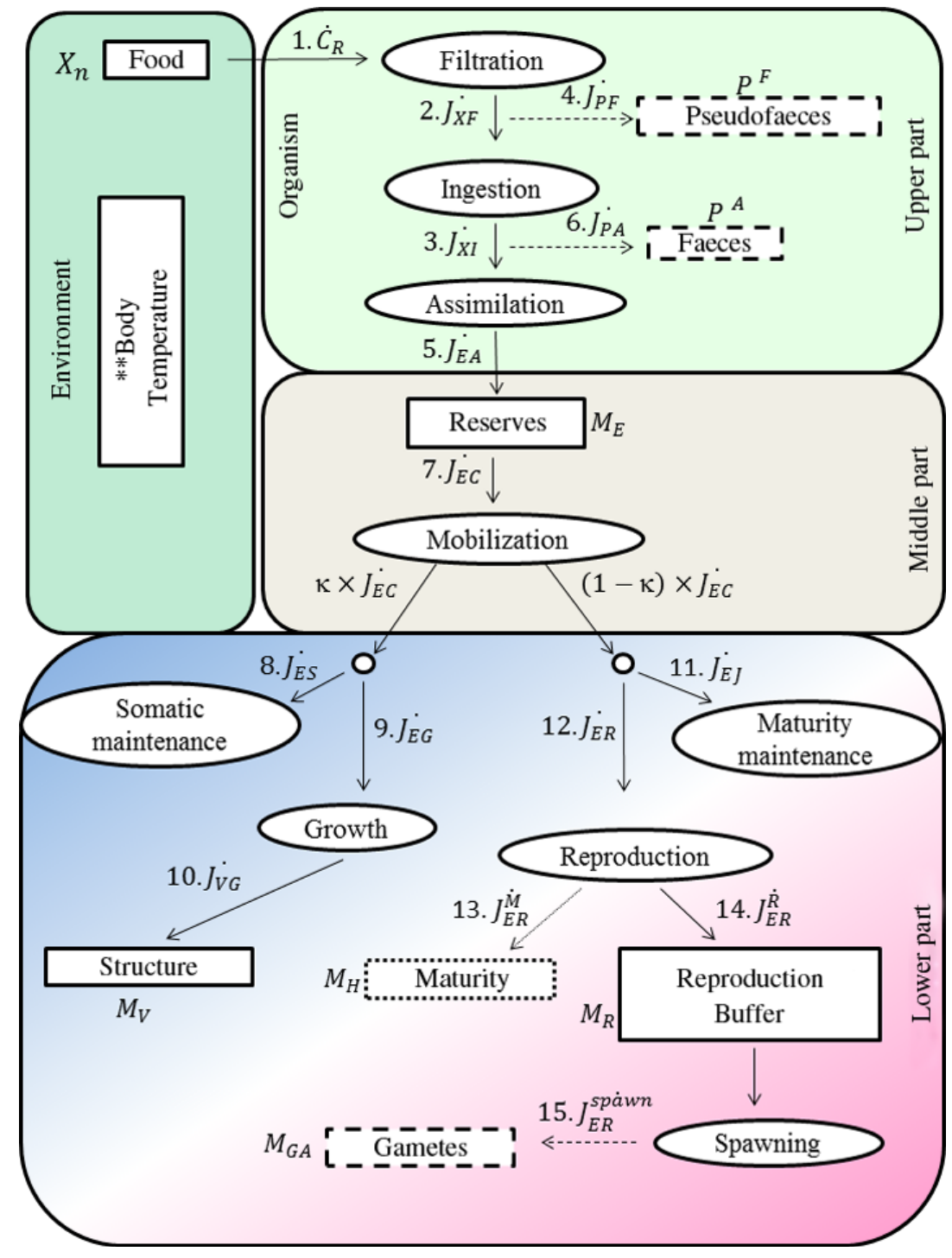

part is stored first and then made available for direct use (and is then available for the lower part). To facilitate understanding by the reader, we will consider the reserves the middle part of the DEB model (Fig. 1; this figure is adapted to bivalves and has been inspired by Sousa et al. 2010 and Saraiva et al. 2012).

\section{Upper part}

Consider a constant amount of food X. The amount of particles that an organism can acquire $\left(X_{n}\right)$ is thus determined by the availability of food and the rate at which the food itself will be removed from the environment. In suspension feeders such as bivalves, for example, the flow of particles that is retained through filtration is equivalent to the product of clearance rate by the total amount of food, $C R \times X_{n}$. Once it arrives in the gills (of bivalves), the food is selected: a fraction $\mathrm{J}_{\mathrm{PF}}$ will be rejected as pseudofaeces, the rest is transported to the mouth to be ingested, $\mathrm{J}_{\mathrm{XF}}$. The ingestion rate $\dot{\mathrm{J}}_{\mathrm{X}}$ is defined as the passage of food to the gut. $\dot{\mathrm{J}}_{\mathrm{X}}$ depends on food availability, body size and temperature and, according to DEB theory, its formulation follows the Holling type II functional response (Holling 1959). It can be calculated as follows:

$\dot{\mathrm{J}}_{\mathrm{X}}=\left\{\mathrm{J}_{\dot{\mathrm{X}}_{\mathrm{m}}}\right\} \times \mathrm{f} \times \mathrm{V}^{2 / 3}$

where $\left\{\mathrm{J}_{\mathrm{X} m}\right\}$ is the area-specific maximum ingestion rate, expressed in $\mathrm{J} \cdot \mathrm{h}^{-1} \cdot \mathrm{cm}^{-2}, \mathrm{f}=\frac{\mathrm{X}}{\left(\mathrm{X}_{\mathrm{k}}+\mathrm{X}\right)}$ is the scaled functional response (range $0-1$ ) with $\mathrm{X}=$ food density ( $\mu \mathrm{g}$ food $\mathrm{l}^{-1}$ ) and $\mathrm{X}_{\mathrm{k}}$ the half saturation coefficient, and $\mathrm{V}$ is the structural body volume. 
The saturation coefficient $\mathrm{X}_{\mathrm{k}}$ depends on food quality and in suspension feeders, for example, it is usually expressed by the concentration of chlorophyll- $a$ ( $\mu$ g Chl- $a$ $1^{-1}$; Sarà et al. 2012); it corresponds to the point where the value of ingestion rate is equal to the half of the maximum. In suspension feeders, the maximum ingestion rate $\dot{\mathrm{J}}_{\mathrm{X}}$ can be derived from ingestion rate measurements (IR, $\mu \mathrm{g} \cdot \mathrm{l}^{-1} \cdot \mathrm{h}^{-1}$ ) based on typical clearance rate (CR) experiments (Sarà et al. 2013).

Hence,

$\left\{\mathrm{J}_{\dot{\mathrm{X}} \mathrm{m}}\right\}=\frac{\mathrm{IR}}{\mathrm{f} \times \mathrm{V}^{2 / 3}}$

where IR is the maximum ingestion rate below the threshold of pseudofaeces production. As filtration and ingestion in bivalves occur simultaneously, the ingestion rate is equal to the filtration rate. The procedure adopted for CR measurements is reported in Widdows \& Staff (2006) and its formulation is derived from Coughlan (1969).

Not all the energy coming from the ingestion process $\left(\dot{J}_{\mathrm{XI}}\right)$ is digested; differences in the chemical composition between bivalve reserve tissue and ingested food determine energy loss $\left(\dot{J}_{\mathrm{PA}}\right)$ as faeces. The assimilation rate $\left(\dot{p}_{\mathrm{A}}\right)$ is the final step of food processing (Saraiva et al. 2011, 2012) and is defined as the process where food is absorbed and converted into the organism's reserves (Kooijman 2010).

The rate of assimilated energy is assumed to be independent of the feeding rate per se but is explicitly related to food density through a functional response curve, so that:

$\dot{\mathrm{p}}_{\mathrm{A}}=\left\{\mathrm{p}_{\dot{\mathrm{Am}}}\right\} \times \mathrm{f} \times \mathrm{V}^{2 / 3}$

where $\mathrm{f}$ is the scaled functional response and $\left\{\mathrm{p}_{\dot{A} \mathrm{~m}}\right\}$ is the maximum assimilation rate per unit surface area. As mentioned above, $\left\{\mathrm{p}_{\dot{A} \mathrm{~m}}\right\}$ describes the efficiency with which energy is converted into the organism's reserve; therefore, it depends on the efficiency of absorption by the organism and on the composition of food. As a main consequence,

$\left\{\mathrm{p}_{\dot{\mathrm{Am}}}\right\}=\mathrm{AE} \times \mu \mathrm{x} \times\left\{\mathrm{J}_{\dot{\mathrm{X}} \mathrm{m}}\right\}$

where AE (range 0-1) is the assimilation efficiency, which is calculated via the Conover ratio (Conover 1966) as traditionally performed in the current literature (Sarà et al. 2000, 2008); $\mu \mathrm{x}$ is the conversion factor of food into energy $\left(\mathrm{J} \cdot \mathrm{mg}^{-1}\right)$ and $\left\{\mathrm{J}_{\dot{\mathrm{X}} \mathrm{m}}\right\}$ is the area specific-maximum ingestion rate, expressed in $\mathrm{J} \mathrm{h}^{-1} \mathrm{~cm}^{-2}$ (see above). At the end of the feeding process, the remaining fraction of energy $\mathrm{J}_{\mathrm{EA}}$ is what is pooled into the reserve compartment.

\section{Middle part}

Reserves represent the core of the DEB theory and are one of the most important advances compared with classical static budget models. As already summarised, reserves collect all the energy coming from the environment minus that spent during the feeding process, $\mathrm{J}_{\mathrm{EA}}$. An important assumption of the DEB model is that neither the feeding process and nor reserves accrue maintenance costs. In the model, the rate at which this energy is used from the reserve is called $\mathrm{J}_{\mathrm{EC}}$, and follows the dynamic according to the $\kappa$-rule. The $\kappa$-rule asserts that a fixed fraction $\kappa$ of assimilated energy is allocated to maintenance and somatic growth, and the remaining fraction $1-\kappa$ is available for maturity maintenance and reproduction. Specifically, the energy mobilised for maintenance and somatic growth is $\kappa \times \mathrm{J}_{\dot{\mathrm{EC}}}$, and that available for maturity maintenance and reproduction is $(1-\kappa) \times \mathrm{J}_{\mathrm{E} C}$.

\section{Lower part}

The lower portion of the DEB model (conceptualised by the lower part in Fig. 1) is characterised by all the processes that require energy expenditures, i.e. energy to be allocated to maintenance of the biomass, development, growth and reproduction. The flux of reserve mobilised for both maintenance and somatic growth $\left(\kappa \times \mathrm{J}_{\dot{\mathrm{EC}}}\right)$, following the $\kappa$-rule, will be equal to $\mathrm{J}_{\dot{\mathrm{EC}}}=\mathrm{J}_{\dot{\mathrm{ES}}}+\mathrm{J}_{\dot{\mathrm{EG}}}$, where $\mathrm{J}_{\mathrm{E}}$ is the flux of energy to be allocated to somatic maintenance and $\mathrm{J}_{\dot{\mathrm{E} G}}$ is that available for the increase in structural body mass. DEB theory stipulates that somatic maintenance has priority over growth and the organism is able to use the reproduction buffer (and in extreme cases the structures) to cope with maintenance costs during starvation periods.

Somatic maintenance $\left(\mathrm{J}_{\mathrm{E} S}\right)$ involves all the processes needed by an organism to simply survive (i.e. ignoring growth and reproduction); as such, it accounts for the flux of reserves allocated to volume (as related to the maintenance of the structures) indicated by the term $\mathrm{J}_{\mathrm{E} M}$, and the flux $\mathrm{J}_{\mathrm{E} T}$ to be devolved to the surface (e.g. heating in endotherms $)$, i.e. $\mathrm{J}_{\mathrm{E} S}=\left(\left[\mathrm{J}_{\mathrm{E} M} \times \mathrm{L}^{3}\right]\right)+\left(\left\{\mathrm{J}_{\mathrm{E}}\right\} \times \mathrm{L}^{2}\right)$.

In ectotherms, therefore, the term $\mathrm{J}_{\mathrm{E} T}$ can be considered null, so that somatic maintenance will depend only on the term $\mathrm{J}_{\mathrm{E} M}$. Indeed, according to the following formula, somatic maintenance is $\mathrm{J}_{\mathrm{E} S}=\left[\mathrm{J}_{\dot{\mathrm{E} M}}\right] \times \mathrm{L}^{3}$, where $\mathrm{L}$ is the individual total length and $\mathrm{J}_{\mathrm{E} M}$ corresponds to maintenance cost scaled with volume, i.e. $\left[\mathrm{J}_{\mathrm{E} M}\right]=\left[\dot{\mathrm{p}}_{\mathrm{M}}\right] \times \mathrm{V}$. The parameter $\left[\dot{\mathrm{p}}_{\mathrm{M}}\right]$ is a good approximation of the organism's basal metabolism and is indirectly related to the measurements of oxygen consumption. The procedures followed for calculating somatic maintenance costs 
are well described in Ren \& Schiel (2008) and Sarà et al. (2013). Furthermore, the energy flux $\mathrm{J}_{\mathrm{E} C}$ mobilised by the reserves also determines the energy to be allocated to growth, $\mathrm{J}_{\dot{\mathrm{E}} \mathrm{G}}$. Growth is considered as the increase in organismal body mass and, following the $\kappa$-rule and somatic maintenance, $\mathrm{J}_{\mathrm{E} G}$ can be calculated via the difference between flux of energy coming from the reserve and the amount of energy allocated to maintenance, i.e. $\mathrm{J}_{\mathrm{EG}}=\left(\kappa \times \mathrm{J}_{\dot{\mathrm{EC}}}\right)-\mathrm{J}_{\mathrm{E} S}$. The model is based on the growth of an organism under constant conditions and the growth rate in the DEB context reduces to the Von Bertalanffy equation with three parameters (time at length zero, growth rate constant and maximum size).

Growth ceases when all reserves are required for somatic maintenance, i.e. when $\mathrm{J}_{\dot{\mathrm{EC}}}=\mathrm{J}_{\dot{\mathrm{ES}}}$. Apart from the individual structural biomass and the reserves, two important variables characterising the organism are maturity level, $\mathrm{M}_{\mathrm{H}}$, and the reproduction buffer. As for somatic maintenance, the maturation/reproduction also needs energy to be maintained. Since both maturity and reproduction are dynamically predicted by the $\kappa$-rule, it follows that $(1-\kappa) \times \mathrm{J}_{\dot{\mathrm{EC}}}=\mathrm{J}_{\mathrm{Ej}}+\mathrm{J}_{\mathrm{ER}}$, where $(1-\kappa) \times \mathrm{J}_{\mathrm{EC}}$ is the flux of energy mobilised from the reserves to be allocated to the reproductive system, $\mathrm{J}_{\mathrm{E} J}$ is the energy needed to support maturity maintenance costs, and $\mathrm{J}_{\mathrm{ER}}$ is the energy available for reproduction. Before an organism is able to produce gametes, a maturation level must be reached. In the standard DEB model, it is assumed that the energy $\mathrm{J}_{\mathrm{ER}}$ is allocated to the maturity buffer during the individual's juvenile stage. Once the maturity level $\left(\mathrm{M}_{\mathrm{H}}\right)$ is reached, the organism become an adult, and a fixed fraction of assimilates is continually transferred from the reserve to the reproduction buffer (after accounting for maturity maintenance) and then to gametes production and spawning. The resulting flux of energy moving into the reproduction buffer is defined as the difference between the energy mobilised from reserves and the costs related to the reaching and maintaining of maturity, so that $\mathrm{J}_{\mathrm{E} R}=(1-\kappa) \times \mathrm{J}_{\dot{\mathrm{EC}}}-\mathrm{M}_{\mathrm{H}}$ (Table 1$)$. The real amount of energy that is stored in reserves $\left[\mathrm{E}_{\mathrm{m}}\right]$ and that is available for reproduction and growth $\left[\mathrm{E}_{\mathrm{G}}\right]$ cannot be estimated directly, but it is possible to derive them from measurements associated with somatic maintenance $\left(\mathrm{J}_{\mathrm{E} S}\right)$ and, specifically, to the related parameter $\left[\dot{\mathrm{p}}_{\mathrm{M}}\right]$. If seasonal patterns of the species are known, these parameters can be estimated from the balance of energy content before and after the growing season, as suggested by literature (van der Veer et al. 2006; Cardoso 2007).

Table 1. Description of the main energy fluxes in the DEB model and their formulation. This table shows only a few processes, for more details see Kooijman (2010), Saraiva et al. (2012) and Sarà et al. (unpublished data).

\begin{tabular}{|c|c|c|c|c|c|}
\hline Process & No. & Symbol & Description & Units & Formulation \\
\hline \multirow[t]{2}{*}{ Filtration } & 1 & $\dot{C}_{R}$ & Clearance - filtration rate & $m^{3} \cdot h^{-1}$ & $\dot{C}_{R}=\frac{\left\{\dot{C}_{R m}\right\}}{\left.1+\sum_{i=0}^{1} \frac{X_{i}}{i} C_{R m}\right\}} V^{2 / 3}$ \\
\hline & 2 & $J_{\dot{X} F}$ & Filtration rate & $\operatorname{molC} d^{-1} \cdot g \cdot d^{-1}$ & $J_{\dot{X}_{F}}=C R X_{n}$ \\
\hline \multirow[t]{2}{*}{ Ingestion } & 3 & $J_{\dot{x} \mid}$ & Ingestion rate & $\operatorname{molC} d^{-1} \cdot g d^{-1}$ & $J_{\dot{X} \mid}=\frac{\rho X_{i} J_{\dot{x} F}}{1+\sum_{i}^{n} \frac{\rho}{X_{i} J_{\dot{x} F}}}$ \\
\hline & 4 & $J_{\dot{P F}}$ & Pseudofaeces production rate & $\operatorname{molC} d^{-1} g d^{-1}$ & $J_{\dot{P F}}=J_{\dot{X} F}+J_{\dot{X} I}^{\dot{x} m}$ \\
\hline \multirow[t]{2}{*}{ Assimilation } & 5 & $\mathrm{~J}_{\text {ĖA }}$ & Assimilation rate & $\mathrm{molC}^{\mathrm{E}} \cdot \mathrm{d}^{-1}$ & $J_{\dot{E} A}=J_{\dot{E} A^{E}}+J_{\dot{E} A^{V}}$ \\
\hline & 6 & $J_{\dot{P A}}$ & Faeces production rate & $\mathrm{molC} \cdot \mathrm{d}^{-1}$ & $J_{\dot{P} A}=J_{\dot{X} \mid}-J_{\dot{E} A}$ \\
\hline Mobilisation & 7 & $J_{\dot{E} \mathrm{C}}$ & Mobilization flux & $\mathrm{molC}^{\mathrm{E}} \mathrm{d}^{-1}$ & $\begin{aligned}\left(\mathrm{J}_{\downarrow} \dot{\mathrm{E} C}\right)_{2} & =[\mathrm{E}] /\left(\left[\mathrm{E}_{\downarrow} \mathrm{G}\right] / \mu_{\downarrow} \mathrm{E}\right. \\
& +\|(\prime \prime[\mathrm{E}])\left(\left[\mathrm{E}_{\downarrow} \mathrm{G}\right]\right) / \mu_{\downarrow} \mathrm{E}\left(\mathrm{V}^{\uparrow}(2 / 3)+\left(\mathrm{J}_{\downarrow} \mathrm{ES}\right)\right)\end{aligned}$ \\
\hline Somatic maintenance & 8 & $\mathrm{~J}_{\mathrm{ES}}$ & Somatic maintenance & $\mathrm{molC}^{\mathrm{E}} \cdot \mathrm{d}^{-1}$ & $\mathrm{~J}_{\dot{\mathrm{ES}}}=\frac{\left[\dot{\mathrm{P}}_{\mathrm{M}}\right]}{\mu_{\mathrm{E}}} \mathrm{V}$ \\
\hline \multirow[t]{2}{*}{ Growth } & 9 & $\mathrm{~J}_{\dot{\mathrm{E}} \mathrm{G}}$ & Flux allocated to growth & $\mathrm{molC}^{\mathrm{E} \cdot d^{-1}}$ & $J_{\dot{E} G}=\left(J_{\dot{E} C}^{\mu_{\mathrm{E}}}\right)-J_{\dot{E} S}$ \\
\hline & 10 & $J_{\dot{V} G}$ & Growth & $\mathrm{molC}^{\mathrm{V} \cdot \mathrm{d}^{-1}}$ & $\mathrm{~J}_{\dot{\mathrm{V} G}}=\mathrm{y}_{\mathrm{VE}}-\mathrm{J}_{\dot{\mathrm{E} G}}$ \\
\hline \multirow[t]{4}{*}{ Maturity reproduction } & 11 & $J_{\dot{E} j}$ & Maturity maintenance & $\mathrm{molC}^{\mathrm{E}} \cdot \mathrm{d}^{-1}$ & $\left.\left(J_{\downarrow} \dot{\mathrm{E} J}\right)=(\downarrow)\right) \mathrm{M}_{\downarrow} \mathrm{H}$ \\
\hline & 12 & $J_{\mathrm{E} R}$ & Flux allocated to reproduction/maturity & $\mathrm{molC}^{\mathrm{E}} \cdot \mathrm{d}^{-1}$ & $J_{\dot{\mathrm{E} R}}=(1-) \mathrm{J}_{\dot{\mathrm{E} C}}-J_{\dot{\mathrm{ES}}}$ \\
\hline & 13 & $J_{E R}^{M}$ & Flux to maturity & $\operatorname{mol} C^{E} \cdot d^{-1}$ & $J_{\dot{E} R}^{M}=\left\{\begin{array}{c}J_{\dot{E} R}, \text { if } M_{H}<M_{H}^{p} \\
0, \text { otherwise }\end{array}\right.$ \\
\hline & 14 & $J_{\mathrm{ER}}^{R}$ & Flux to reproduction buffer & $\mathrm{molC}^{\mathrm{E}} \cdot \mathrm{d}^{-1}$ & $J_{\dot{E} R}^{\dot{R}}=\left\{\begin{array}{l}0, \text { if } M_{H}<M_{H}^{p} \\
J_{\dot{E} R}, \text { otherwise }\end{array}\right.$ \\
\hline Spawning & 15 & $\int_{\dot{E} R}^{\text {spawn }}$ & Spawning & $\mathrm{molC}^{\mathrm{E}} \cdot \mathrm{d}^{-1}$ & $\int_{\mathrm{ER}}^{\text {spawn }}=\left\{\begin{array}{c}k_{R} M_{R} / R^{\text {spawn }}, \text { if } \\
G S R \geq G S R^{\text {spawn }} \wedge T \geq T^{\text {spawn }} \\
0, \text { otherwise }\end{array}\right.$ \\
\hline
\end{tabular}

No., reference number for fluxes as reported in Fig. 1. 


\section{The role of temperature}

As mentioned above, in the standard DEB model the flux of energy inside an organism varies according to its own metabolism and thus depends on physiological rates. Since all physiological rates are strictly dependent on body temperature, it represents an important constraint in the DEB theory.

To include the effect of temperature and within a species-specific range, the description proposed by Arrhenius (1889) usually fits quite well (Kooijman 2010):

$\dot{\mathrm{k}}_{(\mathrm{T})}=\dot{\mathrm{k}}_{1} \times \exp \left\{\frac{\mathrm{T}_{\mathrm{A}}}{\mathrm{T}_{1}}-\frac{\mathrm{T}_{\mathrm{A}}}{\mathrm{T}}\right\}$

where $\mathrm{k}_{(\mathrm{T})}$ is a physiological rate at the ambient temperature $\mathrm{T}$, with $\mathrm{T}$ the absolute temperature (in Kelvin), and $\dot{\mathrm{k}}_{1}$ the physiological rate at the reference temperature $\mathrm{T}_{1}$. $\mathrm{T}_{\mathrm{A}}$ is the Arrhenius temperature. The estimates of Arrhenius temperature $\left(\mathrm{T}_{\mathrm{A}}\right)$ and of the lower and upper boundaries of the tolerance range can be extrapolated from literature data (Cardoso et al. 2006; Pouvreau et al. 2006) or estimated by a direct calculation of physiological rate at different temperatures.

\section{Main DEB model outputs}

The mechanistic nature of the standard DEB model allows the bioenergetics features of an organism to be related to environmental conditions, so that ultimate fitness can be predicted. This is only feasible if the organismal body temperature and concentration of food in the habitat are known, and all DEB parameters of the species are estimated.

The present DEB model allows us to quantify:

1 Maximal habitat individual size (MHIS). It can be calculated as MHIS $=\left(\kappa \times\left(\left\{\mathrm{p}_{\mathrm{AM}}\right\} /\left[\mathrm{p}_{\mathrm{M}}\right]\right)\right)$, where $\kappa$ is the energy fraction allocated to somatic maintenance and growth (i.e. the $\kappa$-rule; Kooijman 2010), $\left\{\mathrm{p}_{\dot{A} \mathrm{~m}}\right\}$ the surface-area specific assimilation rate and $\left[\dot{\mathrm{p}}_{\mathrm{M}}\right]$ is the volume-specific maintenance rate. It is used to explain the link between energy budgets and body size on a local spatial scale.

2 Maturation time (MT). MT is defined as the time in days to reach the minimal size that allows gamete development and maturation. A primary requirement for modelling MT is thus the species-specific information of the smallest size at sexual maturity. This information can usually be extracted from literature, as it is an essential part of many classical biological and ecological studies. Therefore, if we know the smallest size for sexual maturity, the energy flux $1-\kappa$ coming from existing reserves and/or the amount of food energy assimilated (minus maintenance and digestion costs), and assuming that it is used for reproductive purposes (gamete development and maturation, i.e. packaging of energy into gametes), we can estimate the time needed to reach maturity. MT is strictly habitat-specific (i.e. thermal conditions and available food density) as it depends on the specific time required to reach the minimal size threshold for sexual maturity and first spawning.

3 Number of reproductive events per life span (RE). RE is another basal life history trait of organisms that occurs each time the amount of energy has reached a certain density in the reproduction buffer, so that it will overflow as gametes. RE is strictly related to the environmental conditions, as the energy that replenishes the reproduction buffer is dependent on food availability. Furthermore, the standard DEB model assumes that the organism does not spawn until the temperature is above a threshold (Gabbott \& Bayne 1973); this also means that temperature represents a constraint for the occurrence of RE.

4 Total reproductive output (TRO). TRO is the total number of eggs per life span. When the energy of a reproductive buffer reaches a threshold, it is packaged into gametes, which are produced in a discrete number of spawning events. As DEB assumes that the energy needed to build one gamete is usually constant (e.g. $0.0019 \mathrm{~J}$ for one egg in mussels; van der Veer et al. 2006) and that the amount is species-specific, TRO will depend on the amount of energy available for reproduction coming from reserves and stored in a reproduction buffer.

\section{Conclusions}

A major criticism of the functional trait-based mechanistic bioenergetic modelling approach could be that it is based on characteristics of the species' fundamental niche (Kearney \& Porter 2009; Kearney et al. 2010). This view derives from the fact that the approach was welcomed as a sort of 'Holy Grail of ecology' (Lavorel \& Garnier 2002). In reality, it only provides the basal information (i.e. accurate quantitative predictions about the magnitude of life history traits of one species) needed to build the steps towards reaching a complete set of predictions of where a species potentially is able to live and how it reacts, within the species-specific physiological boundaries, to environmental variability. Such information meets one of the most important ecological criteria, which rely on being able to predict species abundance along spatio-temporal environmental gradients.

Being able to make these predictions is the most fundamental aspect of applied ecology, and it is strongly correlated with the ability to predict the future assets of 
biodiversity (Laughlin et al. 2012). An example of this is the ability to quantify TRO within a certain locality. This is one of the most important prerogatives of the mechanistic approach, and represents a more advanced method of predicting the species' presence than other modelling approaches, such as those based on GIS statistical-correlative information (Buckley et al. 2010). These models (e.g. bioclimatic envelope models) use associations between aspects of climate and known distribution occurrences to define sets of conditions under which species are likely to maintain viable populations. They estimate potential distributions (i.e. the geographic projection of the estimated realised niches of species), rather than the occupied distributional area of the species. Although TRO usually defines Darwinian fitness (Bozinovic et al. 2011) and is thus considered a 'surrogate' of the actual individual fitness, it provides fundamental and important information needed to investigate possible distributional ranges of organisms. TRO is a quantitative measure of the reproductive potential of one species. Although it is wellknown that an individual with high gamete production can have very low fitness, for many ecological and management purposes it is of great use to make predictions of where (and when) one organism will display full (e.g. producing millions of eggs) rather than reduced or nil reproductive capacity (e.g. producing only a few eggs or zero). Such an aspect is crucial in free-spawners using external fertilisation - organisms such as bivalves and fish that freely release eggs into the water column (a mechanism representing the major dispersal agent of many marine animals; Duarte 2007). Free-spawners, like most marine organisms (more than 99\%), rely on the reproductive potential of every individual belonging to a population to perpetuate populations, and their ability to colonise contiguous habitats relies on planktonic phases for dispersal (Duarte 2007). Predicting that elements of a certain population of marine ectotherms will be able to produce more eggs than conspecifics, which presents them with major opportunities to perpetuate their genes far beyond their original location and spread to adjacent habitats, to form other nuclei for yet more spreading (Simberloff 2009; Sarà et al. in press-b) is highly valuable information. This is the only modelling approach to date that has the capacity to quantify, mechanistically, the amount of eggs (gametes) producible under environmentally explicit contexts (Sarà et al. 2011, in press-b; Kearney 2012). This represents an important advance in our ability to predict future scenarios in a context of anthropogenic changes. Thus, the presence of one species in a certain place does not depend solely on most elements of the population producing large amounts of gametes (which depends on the magnitude of metabolic machinery functioning) but also on local biological interactions
(Chase \& Leibold 2003). However, being able to predict the potential density (at the net of biotic interactions) is a great help to ecologists, managers and stakeholders and proves crucial on many occasions. Indeed, it has been seen that most ecological interactions are based on density-dependent processes (Ives 2009; Loreau 2010), which also depend on the potential ability that most elements belonging to a certain population have to produce more or fewer gametes along varying environmental gradients.

In conclusion, then, the information derived from the functional trait-based mechanistic model will be useful to identify all the steps in our predictive ability about the effects of anthropogenic stressors on the upper levels of ecological hierarchy (Webb et al. 2010; Laughlin et al. 2012).

\section{Acknowledgements}

This paper has been in part supported by INTERMED, one of the CIRCLE Med projects funded by EU in the framework of Circle ERA Net project (which is funded by the European Commission 6th Framework Programme) and by PRIN TETRIS (2009), funded by Italian Minister of Scientific Research (MIUR). The first author was supported by a Visiting Scholar Award (2012) made by the Office of the Provost at the University of South Carolina. We thank all collaborators and students from EEB lab at UNIPA. We are especially grateful to Brian Helmuth for having initially inspired the first Author to consider the mechanistic approach, to Bas Kooijman and Mike Kearney for having addressed the effort in DEB modelling, John Widdows for allowing the fine tuning of the experimental work at GSaraLab to measure eco-physiological variables in bivalves. The initial metaphor of 'Sicilian gebbia' (i.e. irrigation basin) conceived by Authors, has been refined into the 'Wash Basin' metaphor formulated by Mike Kearney and was adopted in the most recent version of this article.

\section{Author contributions}

G.S.: conceived the idea, led the writing, writing and funding; A.R.: writing; V.M.: writing.

\section{References}

Araujo M.B., Rahbek C. (2006) How does climate change affect biodiversity? Science, 313, 1396-1397.

Arrhenius S. (1889) On the reaction rate of the inversion of non-refined sugar upon souring. Zeitschrift Fur Physikalische Chemie, 4, 226-248.

Bozinovic F., Calosi P., Spicer J.I. (2011) Physiological correlates of geographic range in animals. Annual Review of Ecology Evolution and Systematics, 42, 155-179. 
Buckley L.B., Urban M.C., Angiletta M.J., Crozier L.G., Rissler L.J., Sears M.W. (2010) Can mechanism inform species' distribution models? Ecology Letters, 13, 1041-1054.

Cardoso J.F.M.F. (2007) Growth and reproduction in bivalves: an energy budget approach. Ph.D. thesis, University of Groningen, Groningen, The Netherlands.

Cardoso J.F.M.F., Witte J.I.J., van der Veer H.W. (2006) Intraand interspecies comparison of energy flow in bivalve species in Dutch coastal waters by means of the Dynamic Energy Budget (DEB) theory. Journal of Sea Research, 56, 182-197.

Charnov E.L. (1993) Life History Invariants. Oxford University Press, Oxford: 167.

Charnov E.L., Krebs J.R. (1974) On clutch size and fitness. Ibis, 116, 217-219.

Chase J.M., Leibold M.A. (2003) Ecological Niches: Linking Classical and Contemporary Approaches. University of Chicago Press, Chicago.

Cheung W.W.L., Dunne J., Sarmiento J.L., Pauly D. (2011) Integrating ecophysiology and plankton dynamics into projected maximum fisheries catch potential under climate change in the Northeast Atlantic. ICES Journal of Marine Science, 68, 1008-1018.

Conover R.J. (1966) Assimilation of organic matter by zooplankton. Limnology and Oceanography, 11, 338-354.

Coughlan J. (1969) The estimation of filtering rate from the clearance of suspensions. Marine Biology, 2, 356-358.

Denny M., Benedetti-Cecchi L. (2012) Scaling up in ecology: mechanistic approaches. Annual Review of Ecology Evolution and Systematics, 43, 1-22.

Diaz S., Cabido M. (2001) Vive la difference: plant functional diversity matters to ecosystem processes. Trends in Ecology and Evolution, 16, 646-655.

Duarte C.M. (2007) Marine ecology warms up to theory. Trends in Ecology and Evolution, 22, 331-333.

Einarsson B., Birnir B., Sigurosson S. (2011) A dynamic energy budget (DEB) model for the energy usage and reproduction of the Icelandic capelin (Mallotus villosus). Journal of Theoretical Biology, 281, 1-8.

Gabbott P.A., Bayne B.L. (1973) Biochemical effects of temperature and nutritive stress on Mytilus edulis L. Journal of the Marine Biological Association of the United Kingdom, 53, 269-286.

Hendriks I.E., Duarte C.M., Álvarez M. (2010) Vulnerability of marine biodiversity to ocean acidification: a meta-analysis. Estuarine Coastal and Shelf Science, 86, 157-164.

Hoegh-Guldberg O., Bruno J.F. (2010) The impact of climate change on the world's marine ecosystems. Science, 328, $1523-1528$

Holling C.S. (1959) Some characteristics of simple types of predation and parasitism. Canadian Entomologist, 91, 385-398.

Ives A.R. (2009) Chapter II.2: density dependence and single-species population dynamics. In: Levin S.A., Carpenter S.R., Godfray C.J., Kinzig A.P., Loreau M.,
Losos J.P., Walker B., Wilcove D.S. (Eds), Princeton Guide to Ecology. Princeton University Press, Princeton: 166-171.

Jusup M., Klanjscek T., Matsuda H., Kooijman S.A.L.M. (2011) A full lifecycle bioenergetic model for bluefin tuna. PLOS ONE, 6, e21903.

Kearney M. (2012) Metabolic theory, life history and the distribution of a terrestrial ectotherm. Functional Ecology, 26, 167-179.

Kearney M., Porter W.P. (2009) Mechanistic niche modelling: combining physiological and spatial data to predict species' ranges. Ecology Letters, 12, 334-350.

Kearney M., Simpson S.J., Raubenheimer D., Helmuth B. (2010) Modelling the ecological niche from functional traits. Philosophical Transactions of the Royal Society B: Biological Sciences, 365, 3469-3483.

Kearney M.R., Matzelle A., Helmuth B. (2012) Biomechanics meets the ecological niche: the importance of temporal data resolution. Journal of Experimental Biology, 215, 922-933.

Koen-Alonso M. (2007) A process-oriented approach to the multispecies functional response. In: Rooney N., McCann K.S., Noakes D.L.G. (Eds), From Energetics to Ecosystems: The Dynamics and Structure of Ecological Systems. Springer, Dordrecht: 1-36.

Kooijman S.A.L.M. (2010) Dynamic Energy Budget Theory for Metabolic Organisation, 3rd edn. Cambridge University Press, Cambridge: 508.

Krebs J.R., Davies N.B. (1992) Behavioural Ecology: An Evolutionary Approach. Blackwell Scientific Publications, Oxford: 482.

Laughlin D.C., Joshi C., van Bodegom P.M., Bastow Z.A., Fule P.Z. (2012) A predictive model of community assembly that incorporates intraspecific trait variation. Ecology Letters, 15, 1291-1299.

Lavorel S., Garnier E. (2002) Predicting changes in community composition and ecosystem functioning from plant traits: revisiting the Holy Grail. Functional Ecology, 16, 545-556.

Lima F.P., Burnett N.P., Helmuth B., Kish N., Aveni-Deforge K., Wethey D.S. (2011) Monitoring the intertidal environment with biomimetic devices. In: Cavrak M. (Ed.) Biomimetic Based Applications. InTech, New York: 499-522.

Loreau M. (2010) From Populations to Ecosystems: Theoretical Foundations for a New Ecological Synthesis. Princeton University Press, Princeton: 328 pp.

van der Meer J. (2006) An introduction to Dynamic Energy Budget (DEB) models with special emphasis on parameter estimation. Journal of Sea Research, 56, 85-102.

Pecquerie L., Johnson L.R., Kooijman S.A.L.M., Nisbet R.M. (2011) Analyzing variations in life-history traits of Pacific salmon in the context of Dynamic Energy Budget (DEB) theory. Journal of Sea Research, 66, 424-433.

Pörtner H.O. (2010) Oxygen and capacity limitation of thermal tolerance: a matrix for integrating climate related stressors in marine ecosystems. Journal of Experimental Biology, 213, 881-893. 
Pouvreau S., Bourles Y., Lefebvre S., Gangnery A., Alunno-Bruscia M. (2006) Application of a dynamic energy budget model to the Pacific oyster, Crassostrea gigas, reared under various environmental conditions. Journal of Sea Research, 56, 156-167.

Ren J.F., Schiel D.R. (2008) A dynamic energy budget model: parameterisation and application to the Pacific oyster Crassostrea gigas in New Zealand waters. Journal of Experimental Marine Biology and Ecology, 361, 42-48.

Roff D.A. (1992) The Evolution of Life Histories: Theory and Analysis. Chapman and Hall, New York: 548.

Sarà G., Romano C., Caruso M., Mazzola A. (2000) The new Lessepsian entry Brachidontes pharaonis (Fischer P, 1870) (Bivalvia, Mytilidae) in the western Mediterranean: a physiological analysis under varying natural conditions. Journal of Shellfish Research, 19, 967-977.

Sarà G., Romano C., Widdows J., Staff F.J. (2008) Effect of salinity and temperature on feeding physiology and scope for growth of an invasive species (Brachidontes pharaonis Mollusca: Bivalvia) within the Mediterranean sea. Journal of Experimental Marine Biology and Ecology, 363, 130-136.

Sarà G., Kearney M., Helmuth B. (2011) Combining heat-transfer and energy budget models to predict local and geographic patterns of mortality in Mediterranean intertidal mussels. Chemistry and Ecology, 27, 135-145.

Sarà G., Reid G., Rinaldi A., Palmeri V., Troell M., Kooijman S.A.L.M. (2012) Growth and reproductive simulation of candidate shellfish species at fish cages in the southern Mediterranean: dynamic Energy Budget (DEB) modelling for integrated multi-trophic aquaculture. Aquaculture, 324-325, 259-266.

Sarà G., Palmeri V., Montalto V., Rinaldi A., Widdows J. (2013) The parameterisation of bivalve functional traits in a context of mechanistic ecophysiological Dynamic Energy Budget models. Marine Ecology Progress Series, 480, 99-117. Sarà G., Palmeri V., Rinaldi A., Montalto V., Helmuth B. (in press-a) Predicting biological invasions in marine habitats through eco-physiological mechanistic models: a study case with the bivalve Brachidontes pharaonis. Diversity and Distribution. doi: 10.1111/ddi.12074

Sarà G., Milanese M., Prusina I., Sarà A., Angel D.L., Glamuzina B., Nitzan T., Freeman S., Rinaldi A., Palmeri
V., Montalto V., Lo Martire M., Gianguzza P., Arizza V., Lo Brutto S., De Pirro M., Helmuth B., Murray J., De Cantis S., Williams G.A. (in press-b) The impact of climate change on Mediterranean intertidal communities: losses in coastal ecosystem integrity and services. Regional Environmental Change. doi: 10.1007/s10113-012-0360-z.

Saraiva S., van der Meer J., Kooijman S.A.L.M., Sousa T. (2011) Modelling feeding processes in bivalves: a mechanistic approach. Ecological Modelling, 222, 514-523.

Saraiva S., van der Meer J., Kooijman S.A.L.M., Witbaard R., Philippart C.J.M., Hippler D., Parker R. (2012) Validation of a dynamic energy budget (DEB) model for the blue mussel Mytilus edulis. Marine Ecology Progress Series, 463, 141-158.

Schoener T.W. (1986) Mechanistic approaches to community ecology: a new reductionism? American Zoologist, 26, 81-106.

Simberloff D. (2009) The role of propagule pressure in biological invasions. Annual Review of Ecology, Evolution, and Systematics, 40, 81-102.

Sokolova I.M., Frederich M., Bagwe R., Lannig G., Sukhotin A.A. (2012) Energy homeostasis as an integrative tool for assessing limits of environmental stress tolerance in aquatic invertebrates. Marine Environmental Research, 79, $1-15$.

Sousa T., Domingos T., Poggiale J.C., Kooijman S.A.L.M. (2010) Dynamic energy budget theory restores coherence in biology. Philosophical Transactions of the Royal Society B: Biological Sciences, 365, 3413-3428.

Stearns S.C. (1992) The Evolution of Life Histories. Oxford University Press, Oxford: 262.

van der Veer H.W., Cardoso J.F.M.F., Van der Meer J. (2006) The estimation of DEB parameters for various North Atlantic bivalve species. Journal of Sea Research, 56, 107-124.

Webb C.T., Hoeting J.A., Ames G.M., Pyne M.I., Poff N.L. (2010) A structured and dynamic framework to advance traits-based theory and prediction in ecology. Ecology Letters, 13, 267-283.

Widdows J., Staff F. (2006) Biological effects of contaminants: measurement of scope for growth in mussels. ICES Techniques in Marine Environmental Sciences, 40, 1-30. 